and creep testing in both tension and compression was in progress, and the use of strain gauges for evaluation of residual stresses and for recording movements in large structures was illustrated. In the Corrosion Section work was in progress on vapour-phase impregnation of iron and steel with silicon, hydrogen embrittlement of steel, and electrodeposition of manganese. Attention was directed to the marked influence of directionality in light-alloy extrusions on resistance to corrosion and stress corrosion.

A large proportion of the equipment and apparatus on view had been constructed in the laboratory workshops, including the pilot plant for aluminium distillation, the vacuum induction and are-melting furnaces, gas X-ray sets, compression creep machines, furnaces and temperature controllers.

\section{INDIAN ASSOCIATION FOR THE CULTIVATION OF SCIENCE}

$T$

HE annual report of the Indian Association for the Cultivation of Science for $1951-52^{*}$ records the completion of the transfer to the Association's new buildings at Jadarpur and the removal of the Department of Organic Chemistry in June 195 I, but research work was considerably curtailed by the removal. Research schemes for the X-ray study of coal and for the construction of osmometers for highpolymer research, sanctioned by the Council of Scientific and Industrial Research, were continued, and a new scheme was sanctioned for the construction of a light-scattering apparatus for measuring the molecular weight, size and shape of high polymers.

In the Department of X-rays and Magnetism a systematic investigation has been undertaken into the structures of phenanthrene derivatives, particularly hormones, and N. N. Gupta has been able to show that the nature of the low-angle scattering of X-rays does not depend upon the internal structure of the crystal but only on the size and shape of the particle. R. K. Sen has perfected the method of determining the elastic constants of a crystal by the $\mathrm{X}$-ray diffraction method, and the limitations of the Jahn--Jeller effect have been investigated. Measurement of the conductivity of single crystals of graphite from $80^{\circ}$ to $500^{\circ} \mathrm{K}$. has been completed, as well as the major equipment for the liquid hydrogen plant.

In the Department of Optics, studies on $p$-dichlorobenzene have shown that crystals cooled once below $0^{\circ} \mathrm{C}$. give a different Raman spectrum from crystals not treated thus. New lines in the low-frequency region have been observed in the Raman spectra of 0 -xylene and benzyl bromide, and the ultra-violet absorption spectra of acetophenone, methyl benzoate ethylbenzene and isopropylbenzene have been studied in the liquid and solid states, as well as those of the cresols, $o$ - and $p$-xylene, benzyl alcohol and benzyl chloride. In the Department of Theoretical Physics, besides work on the meson fields and nuclear scattering, good progress has been made in improving the Born approximation by taking higher terms of a consistent expansion in powers of the constant denoting the strength of the coupling between the field and the particle.

In the Department of Physical Chemistry detailed study has been undertaken of chain transfer in * Ir dian Association for the Cultivation of Science. Annual Rerort for 1951-52. Pp. ii +40. (From the Association, Calcutta $32 ; 1952$.) uncatalysed polymerization of styrene methyl methacrylate and methyl acrylate in solvents, and investigations have also been made of the polymerization of methyl methacrylate with hydrogen peroxide in nonaqueous solvents, triphenylmethylcellulose and the solubilization of mixed detergents. In the Department of Inorganic Chemistry, which formally started in July 1951, preliminary investigations were made on co-ordination complexes and ion-exchange methods in inorganic chemistry. Lists of papers published during the year are included, with lists of books and periodicals added to the Library.

\section{THE CHAYEN PROCESS FOR} EXTRACTION OF OILS AND FATS

T

HE normal process for the extraction of oils and fats from naturally occurring cellular material involves the use of a hot solvent. This process requires steam heating for many hours, resulting in the formation of some undesirable degraded products.

British Glues and Chemicals, Ltd., gave a demonstration of a new process devised by Mr. I. H. Chayen and his associates at their Stratford factory in London on October 28, when they were able to show an entirely new technique. In this process, crushed bones are passed, together with a stream of water, into a modified disintegrator where complete fat rendering is achieved in about one second while the material is in the mill. In this disintegrator, the normal blades had been replaced by beaters arranged to give a clearance of about 4 in. from the millcasing. With a blade tip-speed of about 12,000 ft. per min., the high-speed impulses given to the water break open the cell-walls of the tissue and enable an easy extraction to follow.

The fat and degreased bone leaving the mill are separated by gravity from the water stream, the fat being skimmed off and purified and the bones passed on for drying, when they are ready for glue making or for incorporation in bone meal.

The importance of this technique lies not only in the fact that it has provided a much improved process for one industry, but also that it has provided a now chemical engineering tool and principle, namely, the use of high-speed impulses to break down mechanical barriers, in this case the cell-walls. The application of high-speed vibrations in the chemical process industries is as yet a largely unexplored field, but this application is already showing a great reward. The degreased bone is ready for glue making in $8 \mathrm{~min}$. and the fats are of much finer quality, since the process is carried out in the cold. The continuous process offers many advantages compared with the old batch one in the form of simplified plant layout and operation, as well as very considerable saving in fuel.

This is an interesting example of a machine produced for one purpose being applied with but small alteration to provide a new mechanism in another industry. British Glues, Ltd., are to be congratulated not only on their discovery of a new principle, but also on the quick way in which they have passed from the pilot plant to the commercial plant, for they now have this process in use in four factories, including one in Canada. They were able to show on a pilot plant the same technique for handling herrings, and the next development may well be in the valuable fish-liver industry.
J. M. COULSON 